after the operation, and naturally some months have walls of each place can then be properly cleansed and elapsed before they were in the usual condition of the bed pushed back.

physical health. This is especially the case where the Any one of us would, I am sure, prefer a dormitory bromid habit has been broken up in conjunction with of this sort to one where there is common air space the castration, or a short time subsequent to it. The for all.

question as to whether resection of the cord would be With epileptic children the clothing is kept on the followed by advantages equal to those coming after bed much better than in any other way and, in fact, it the removal of the glands has not been investigated. would be really difficult for the patient to get himself

The effect on girls has been noted in only two cases. uncovered enough to take cold.

These were subjected to operation before coming Opposite each alcove is a ventilated space for the here. The results in these instances have seemed to patient to hang his day garments. The windows in fully justify the procedure.

\section{ALCOVE BEDS FOR THE EPILEPTIC.}

Presented to the Section on State Medicine at the Forty-eighth Annual Meeting of the American Medical Association, held at Philadelphia, June 1-1, 1897.

BY EVERETT FLOOD, M.D. BA LJWINSYLLE, MASs.

In presenting this subject I labor under the disadvantage of advocating a theory rather than a well demonstrated fact. Caring for the epileptic in such beds as I am about to describe has, so far as I am able to learn, never been tried. An approach has been made to it in a few places, especially in the asylum at Turin, where very narrow rooms are used, but the essential features of this plan are lacking.

The method is not advanced as a plan to be followed in all cases, but as apparently well adapted to certain conditions. The idea is to make an alcove, with walls of any firm material, either plank or brick, or brick with plank or board cover, just wide enough to easily admit the fully made-up bed. The bed should run on easy rollers and possibly project a few inches out of its alcove: There may be one alcove or many, side by side. This kind of a dormitory may be constructed on the ground floor or any floor above, provided the foundations are suitably strengthened, and no very great weight is added by this kind of construction. Each alcove is to have a suitable fresh-air ingress and a proper outlet for the warmed air. There may be a door to the stall or not, according to requirements. If a door is desired, then the bed can not project beyond the sides of the alcove, but may be flush with them.

There may be a single row of alcoves, or a double row in the middle of the room, or a single row at one side, or a row on each side. The better way would seem to be to have five to ten alcoves in each row. A double row head-to-head, running through the middle of the room so that the watchman can easily walk around the whole is the plan mainly considered.

The patient gets into bed over the foot, or the bedstead may be withdrawn, the patient is tucked in by the attendant and the bed then pushed back into its alcove. Experiments have been tried with different materials, and it is shown that sounds from one alcove to another can be so deadened that no serious discomfort would be occasioned by such noises as are ordinarily heard from this class of persons, while odors from one to another aré absolutely prevented and each patient is breathing pure air. If a bed becomes soiled and is withdrawn from the alcove then odors might be perceived in the adjoining places, but the bed can be quickly stripped, the bedding thrown into the shute, which is conveniently placed, and ventilated, while the patient is being attended to in the bath. To make up these beds they must be withdrawn from the alcove and the clothing adjusted. The floor and this room are above such closed spaces.

The night nurse goes around quietly looking into each alcove in the row, or in the double rows, and need not disturb any patient either with her light or by any noise she might need to make.

The cost of such construction as this would manifestly be greater than for the ordinary dormitory, for it is natural to suppose that a room especially adapted to the use of this class of patients will cost more than one designed only for the ordinary insane or demented patient. The result to be reached is a more difficult one.

Details for the construction of the remaining parts of the building have been worked out, but need not essentially differ from other asylum buildings.

\section{RELATION OF RAILWAY COMPANIES TO} STATE BOARDS OF HEALTH.

Presented to the Section on State Medicine at the Forty-eighth Annual Meeting of the American Medical Association, at Philadelphia, Pa.. June 1-4, 1897.

BY G. P. CONN, A.M., M.D.

CHIEF SURGEON BOSTON AND MAINE KAILWAY, CONCORD, N, H.

In the last twenty years it has become a well-settled fact that State boards of health are primarily intended to take cognizance of the interests of health and life among the people of the State; and while it may be true that the work of a State board is to a considerable extent educational in its character, yet its scope is practically unlimited. Its observations and duties should not only pertain to the physical welfare of every citizen of a State, but business interests should receive due attention and the commercial relation of State, federal and international prosperity should never be ignored nor forgotten. Therefore, a bureau of health becomes an integral part of the executive department of a State, around which every citizen has the "inalienable right to life, liberty and the pursuit of happiness."

Such conditions represent the brightest and most potent exponents of a higher civilization, in which robust health for all classes of people is made possible. State pride is quite universal and progressive prosperity becomes a motto for every person as well as every vocation.

As an introduction to the subject I propose to briefly discuss and bring to the notice of this National Association, the above will serve to outline and emphasize the fact that hygiene, in effecting the moral and physical conditions of the inhabitants of every community, State or nation, must directly or indirectly have an influence in all business pursuits, including State, federal and international transportation.

It is a topic of much importance and, in a brief paper, can not be fully considered and therefore I can only hope to present to your notice a few of the more 